\title{
Transportation Planning Using Conventional Four Stage Modeling : An Attempt for Identification of Problems in a Transportation System
}

\section{Geetanjali Yadav ${ }^{1}$, Sujesh D Ghodmare ${ }^{2}$}

1P.G. Research Scholar, Department of Civil Engineering, G H Raisoni College of Engineering, Nagpur, Maharashtra, India

${ }^{2}$ Assistant Professor, Department of Civil Engineering, G H Raisoni College of Engineering, Nagpur, Maharashtra, India

\begin{abstract}
Article Info

Volume 8, Issue 4

Page Number : 556-567

Publication Issue

July-August-2021

\section{Article History}

Accepted : 07 Aug 2021

Published : 14 Aug 2021

In the formative development of urban transportation planning, travel forecasting is essential. Various travel simulation techniques are used to estimate possible traffic scenarios. It's been used to analyze road capability, transportation system developments, and new land use strategies and policies. The solution to travel decisions is generally obtained if the models are done in sequence. Many attempts are made to simulate the variety of choices made by travellers as a part of a response to a particular highway system, related transit system, and connected policies. For this purpose number of assumptions are considered regarding the decisions made by the people, factors considered by them, and their reaction as a response to the alternatives available in the transportation system. Generally, the process of travel simulation follows trip generating at the trip generation zone and moves through different links of the network and nodes. It ultimately ends at the trip attraction zone. The simulation method is known as Traditional Four Steps Transportation Modeling, and it includes the four basic models namely Trip Generation, Trip Distribution, Mode Choice, and Traffic Assignments. This paper it is tried to focus on the process of this traditional four-step transportation modeling system. The modeling method calculates a simplified transportation network from the city of Ulhasnagar, India.

Keywords :- Travel simulation, four steps transportation modeling, Mathematical model, Ulhasnagar city.
\end{abstract}

\section{INTRODUCTION}

Passenger transportation is vital to the city's operation, and transportation is the backbone of urban management. One of the most important factors is transit planning and infrastructure growth, which is particularly important in major metropolitan areas with a high and rapid population growth [1]. It is essential to have a clear understanding of current travel patterns in order to identify and represent a 
diverse traffic problems. To manage, develop, evaluate, and regulate transportation and supply chain networks, precise forecasts of total passenger and freight demand, as well as efficient and comparable transportation connections, are needed [11]. The main objective of transportation planning and management is to strike a balance between transportation supply and travel demand. Transportation planning implements a decisionmaking process for future road infrastructure improvements in a region. To guide in the decisionmaking process, various programming software and manuals have been generated. [2] Is one of the most essential processes?

1. Simulations for calculating travel demand for the four-step planning phase.

2. Measurements of transport costs that provide details on regional congestion in the city.

Travel demand analysis methods are used for the four-step urban planning process. In relation to rising in regional development and road network supply, travel forecasting models are used to estimate changes in traffic patterns and the operation of the transportation system. Travel demand modelling is a challenging task, but it is crucial for good transportation planning and analysis [1]. The aims of this project are just to gain a clearer knowledge of the traffic situation in Ulhasnagar, Maharashtra, on a zonal basis, and to improve network Assignment by using Urban Transport Modeling System.

\section{STUDY AREA}

The data collection for this study has been chosen from Ulhasnagar Municipal Corporation area [5]. Ulhasnagar town, Thane district, Maharashtra has 5 camps. Ulhasnagar 1, Ulhasnagar 2, Ulhasnagar 3, Ulhasnagar 4, Ulhasnagar 5 are examples. The city is surrounded into 20 zones and 78 wards. For this project, 6 zones from Ulhasnagar camp no. 4 have chosen as traffic analysis area.

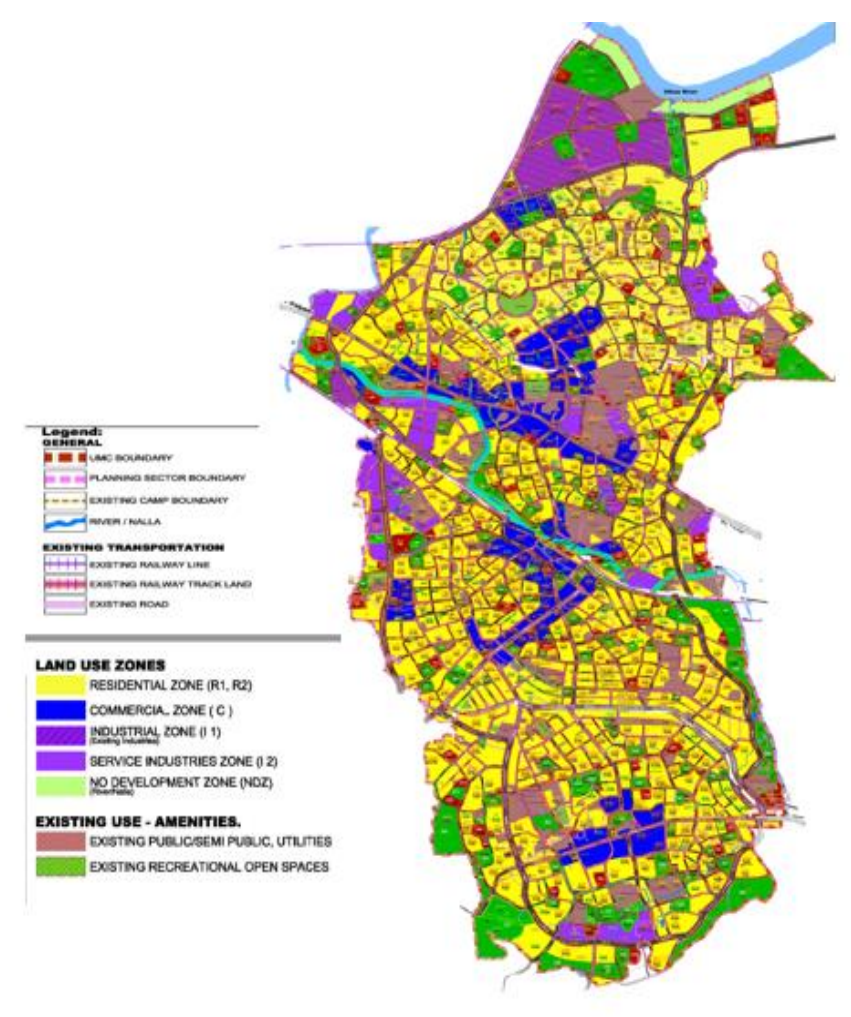

Figure 1 : Ulhasnagar city Corporation (study area) Source: Ulhasnagar Municipal Corporation, 2020

\section{METHODOLOGY}

To achieve the goals of this research paper, the traditional four-step transportation modelling system is used. It's a technique for performing at a macro level [6]. In the next section, you must complete the following four steps:

\section{TRIP GENERATION}

The traditional four-step transportation planning model, which is commonly used for forecasting travel demand, begins with trip generation. It forecasts the number of trips departing from or arriving at a specific traffic analysis zone [3]. The number of people in the household and the number of vehicles available are used to produce trips. Usually, trip attractions are measured by the level of workforce in a particular interval.

This stage describes trip production and attraction after ten years (2021) (base year 2011). To continue, 
actual trip production and attraction parameters are These growth rates are based on a region basis [4]. calculated using 10-year growth rates (Figure 1). Tables 2 and 3 have been provided using Figure 1.

\section{Growth rate}

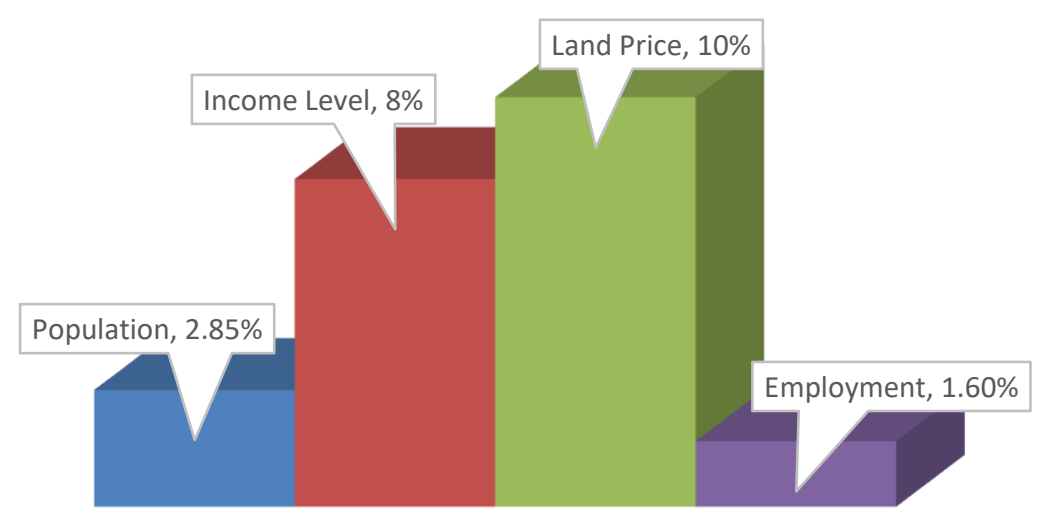

Figure 1 shows the growth value of various components after ten years.

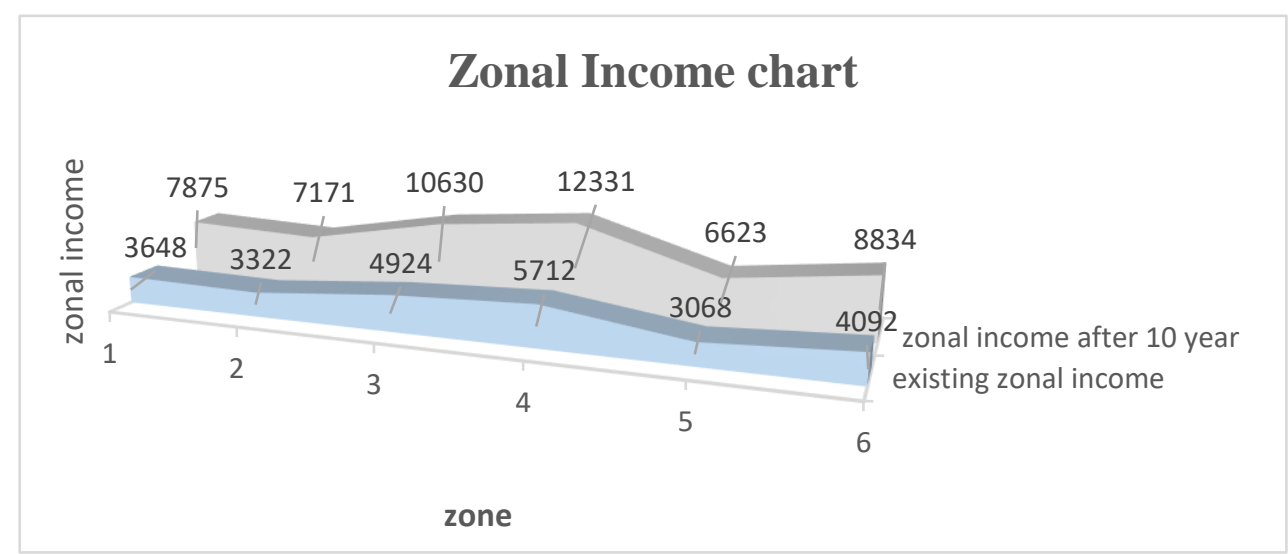

Figure 2 shows the existing and after 10 year population values

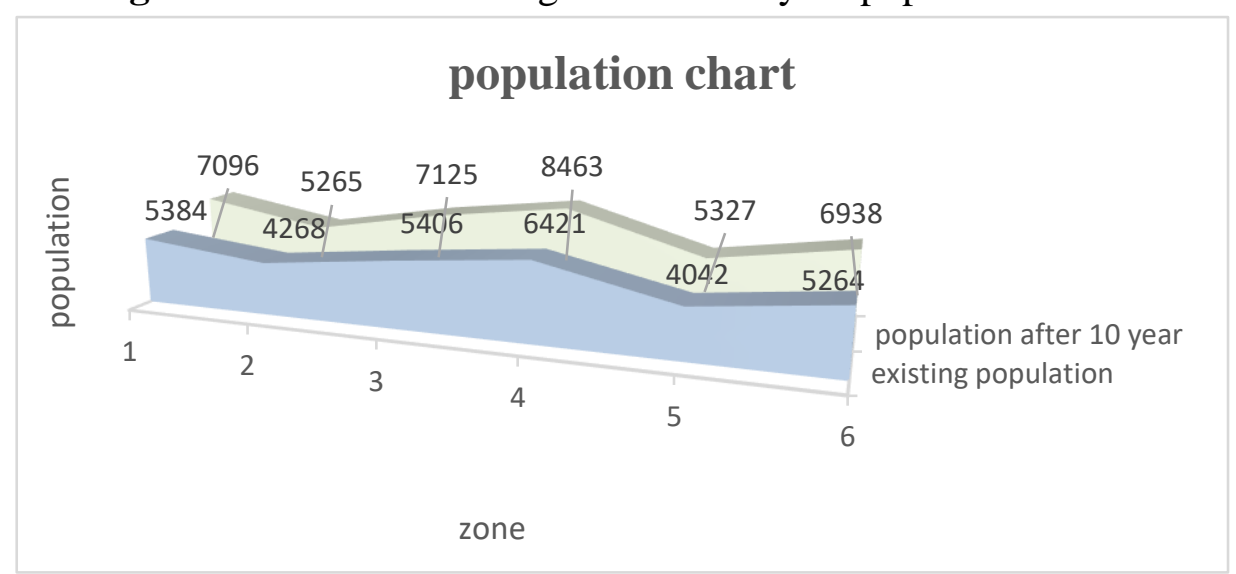

Figure 3 existing and after 10 year zonal income values 
For trip production analyses, the population and zonal income graph is used.

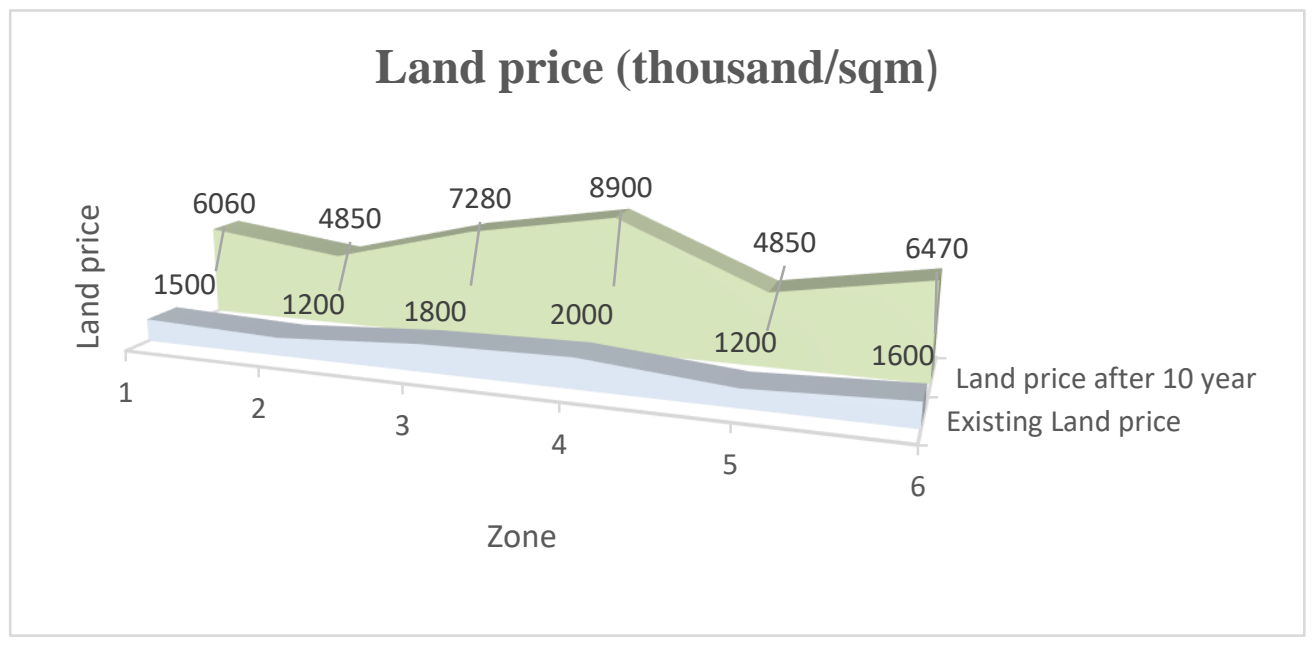

Figure 4 existing and after 10 year employment details

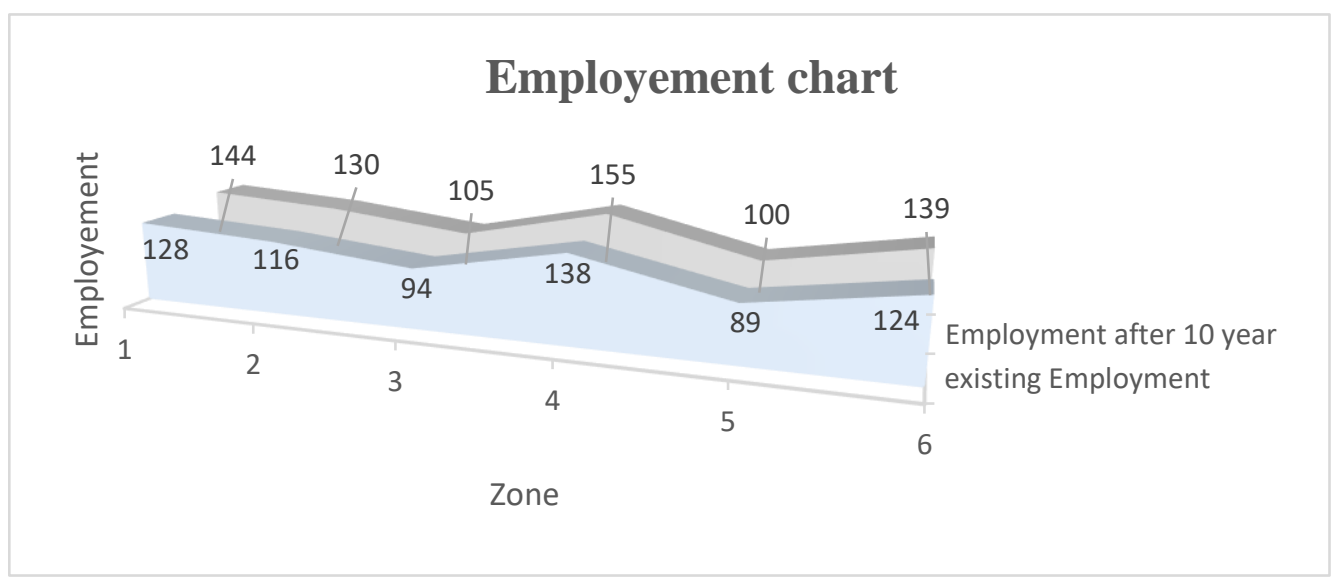

Figure 5 existing and after 10 year land price value in thousand /sqm

For trip attraction analyses, the employment and land price graph is used. Calculation process for future forecasting (2031): -

\section{Existing values $x(1+\text { growth rate })^{\wedge}$ projected year}

As a result, forecasted values for either trip production and attraction variables are calculated using similar formulas. Two regression equations are identified from the measured variables for trip production and trip attraction after 10 years [2]. The two additional regression equations have been found:

For trip production: $Y_{\text {Production }}=4.251743-0.02181 X X_{1}+0.3285 X X_{2}$

For trip attraction: $Y_{\text {Attraction }}=3.88933-0.000571 X X_{1}+0.0003863 X X_{2}$

These regression equations are then used to determine travel simulations for both trip production and attraction after 10 years. After identifying possible productions and attractions, the stage of trip generation comes to an end. 


\section{TRIP DISTRIBUTION}

Enable the collection of trip productions and trip attractions, the next step is to arrange the productions and attractions in order to evaluate how trips created in one zone are divided across all other zones. To put it simply, it's the method of predicting how people will choose their ultimate destinations. There are a variety of reasons why one location is preferred over another. In general, traffic distribution is a function of [8]

1. population socioeconomic characteristics,

2. transportation facility type and extent, and

3. Land-use pattern, including position and intensity.

The first step in the trip distribution process will be to develop an origin-destination matrix for each of six zones.

Table 1: Origin-Destination (OD) matrix

\begin{tabular}{|l|l|l|l|l|l|l|l|}
\hline O-D & ZONE1 & ZONE2 & ZONE3 & ZONE4 & ZONE5 & ZONE6 & TOTAL \\
\hline ZONE1 & & & & & & & 2436 \\
\hline ZONE2 & & & & & & & 2245 \\
\hline ZONE3 & & & & & & & 3341 \\
\hline ZONE4 & & & & & & & 3870 \\
\hline ZONE5 & & & & & & & 2064 \\
\hline ZONE6 & & & & & & & 2754 \\
\hline TOTAL & 1500 & 1200 & 1800 & 2000 & 1600 & 1200 & 9300 \\
\hline
\end{tabular}

Total trip production value is 16705 and total trip attraction is 9300, Therefore trip Production > trip Attraction. The adjustment factor is used to create trip attraction equivalent to trip production [2].

$$
\text { Adjustment factor }=\frac{\text { Trip production }}{\text { Trip attraction }} * \text { Trip attraction value }
$$

Table 2 : Adjusted origin-destination matrix

\begin{tabular}{|l|l|l|l|l|l|l|l|}
\hline O-D & one1 & zone2 & zone3 & zone4 & zone5 & zone6 & total \\
\hline zone1 & & & & & & & 2436 \\
\hline zone2 & & & & & & 245 \\
\hline zone3 & & & & & & 334 \\
\hline zone4 & & & & & & 3870 \\
\hline zone5 & & & & & & 2064 \\
\hline Total & 2700 & 2160 & 3240 & 3600 & 2160 & 2880 & 19920 \\
\hline
\end{tabular}

The path overload makes it difficult to move from one node to another in a network. While 'Link Impedance' can be expressed as a duration for modelling purposes, travel time or apparent costs are typically more correct measures. Now that a cost matrix has been formed (in terms of time), table 3 is constructed by estimating the cost of travel from one zone to another. The gravity model is used in trip distribution stage. 
Table 3: Cost matrix table $(\mathrm{C}$ in) in terms of time

\begin{tabular}{|l|l|l|l|l|l|l|}
\hline O-D & Zone1 & Zone2 & Zone3 & Zone4 & Zone5 & Zone6 \\
\hline Zone1 & 0.368 & 0.223 & 0.135 & 0.165 & 0.135 & 0.111 \\
\hline Zone2 & 0.223 & 0.368 & 0.165 & 0.135 & 0.202 & 0.165 \\
\hline Zone3 & 0.135 & 0.165 & 0.368 & 0.223 & 0.202 & 0.135 \\
\hline Zone4 & 0.165 & 0.135 & 0.223 & 0.368 & 0.110 & 0.165 \\
\hline Zone5 & 0.135 & 0.202 & 00.202 & 0.111 & 0.368 & 0.302 \\
\hline Zone6 & 0.111 & 0.165 & 0.135 & 0.165 & 0.302 & 0.368 \\
\hline
\end{tabular}

Impendence factor $=e^{-\beta * C_{i j}}$

Table 4: Impedance factor values

\begin{tabular}{|l|l|l|l|l|l|l|l|}
\hline O-D & Zone 1 & Zone 2 & Zone 3 & Zone 4 & Zone 5 & Zone 6 & Total \\
\hline Zone1 & 465 & 282 & 171 & 209 & 171 & 140 & 1438 \\
\hline Zone2 & 282 & 465 & 209 & 171 & 255 & 209 & 1591 \\
\hline Zone3 & 171 & 209 & 465 & 282 & 255 & 171 & 1553 \\
\hline Zone4 & 209 & 171 & 282 & 465 & 140 & 209 & 1476 \\
\hline Zone5 & 171 & 255 & 255 & 140 & 465 & 382 & 1668 \\
\hline Zone6 & 140 & 209 & 171 & 209 & 382 & 465 & 1576 \\
\hline Total & 1450 & 1590 & 1540 & 1470 & 1670 & 1580 & 9300 \\
\hline
\end{tabular}

Therefore, total impendence factor is 7.3595 and total trip is 9300

The trip to every zone with different zones is now calculated using the formula below.

Trip of any zone $=\frac{\text { Total trip }}{\text { Total impendence factor }} *$ Impendence factor for the particular zone

Table 5: Trip distribution for future forecasting

\begin{tabular}{|l|l|l|l|l|l|l|}
\hline O-D & Zone 1 & Zone 2 & Zone 3 & Zone 4 & Zone 5 & Zone 6 \\
\hline Zone1 & 10 & 15 & 20 & 18 & 20 & 22 \\
\hline Zone2 & 15 & 10 & 18 & 20 & 16 & 18 \\
\hline Zone3 & 20 & 18 & 10 & 15 & 16 & 20 \\
\hline Zone4 & 18 & 20 & 15 & 10 & 22 & 18 \\
\hline Zone5 & 20 & 16 & 16 & 22 & 10 & 12 \\
\hline Zone6 & 22 & 18 & 20 & 18 & 12 & 10 \\
\hline
\end{tabular}

Now, comparing Tables 2 and 5, it is clear that the trip productions and trip attractions are vastly different from what they should be. Although the overall number of trips is the same, there are variations in total output and attraction between zones. This indicates that the inter-zonal distribution is incorrect.

Table 6: Adjusted trip distribution after 10 years

\begin{tabular}{|l|l|l|l|l|l|l|l|}
\hline O-D & Zone $\mathbf{1}$ & Zone 2 & Zone 3 & Zone 4 & Zone 5 & Zone 6 & Total \\
\hline Zone1 & 406 & 449 & 363 & 381 & 426 & 411 & 2436 \\
\hline Zone2 & 436 & 271 & 368 & 559 & 209 & 402 & 2245 \\
\hline Zone3 & 508 & 344 & 627 & 556 & 723 & 832 & 3341 \\
\hline Zone4 & 483 & 540 & 804 & 752 & 362 & 929 & 3870 \\
\hline Zone5 & 476 & 180 & 497 & 521 & 173 & 217 & 2064 \\
\hline
\end{tabular}




\begin{tabular}{|l|l|l|l|l|l|l|l|}
\hline Zone6 & 391 & 376 & 581 & 831 & 267 & 338 & 2754 \\
\hline Total & 2700 & 2160 & 3240 & 3600 & 2160 & 2880 & 19920 \\
\hline
\end{tabular}

Adjusted trips from various zones are found to solve the problem. After 10 years, this is the final O-D matrix for trip distribution among different zones.

Finally, trip distribution from one zone to different ends at the result.

\section{MODAL SPLIT}

The process of separating person-trips by mode of travel is known as modal split. In general, modal split refers to trips taken by private car rather than public road or rail transportation. One of the most important parts of the travel demand modelling process is mode selection [16]. The 'Logit' model is a regularly adopted model for mode split [2]. This step provides a matrix for calculating the utilities for two modes of transportation: car and rickshaw. Furthermore, utility functions are assumed for these tow modes.

The following are the utility functions [4]:

$$
\begin{gathered}
U_{\text {car }}=-0.60 \text { Travel Time }-0.040 \text { Travel Cost \& } U_{\text {Auto }}=1.2-0.060 \text { Travel Time }- \\
\text { 0.040Travel Cost }
\end{gathered}
$$

Table shows utility matrix tables for various modes of transportation.

Table 7: Utility matrix for car

\begin{tabular}{|l|l|l|l|l|l|l|}
\hline O-D & Zone1 & Zone2 & Zone3 & Zone4 & Zone5 & Zone6 \\
\hline Zone1 & -1.2 & -1.7 & -2.08 & -1.8 & -2.08 & -2.32 \\
\hline Zone2 & -1.7 & -1.2 & -1.88 & -2.08 & -1.68 & -1.88 \\
\hline Zone3 & -2.08 & -1.88 & -1.2 & -1.62 & -1.76 & -2.08 \\
\hline Zone4 & -1.8 & -2.08 & -1.62 & -1.2 & -2.32 & -1.88 \\
\hline Zone5 & -2.08 & -1.68 & -1.76 & -2.32 & -1.2 & -1.44 \\
\hline Zone6 & -2.32 & -1.88 & -2.08 & -1.88 & -1.44 & -1.2 \\
\hline
\end{tabular}

Table 8: Utility matrix for rickshaw

\begin{tabular}{|l|l|l|l|l|l|l|}
\hline O-D & Zone1 & Zone2 & Zone3 & Zone4 & Zone5 & Zone6 \\
\hline Zone1 & 0.32 & -0.3 & -0.8 & -1.02 & -0.92 & -1.36 \\
\hline Zone2 & -0.3 & 0.32 & -0.42 & -0.56 & -0.34 & -0.72 \\
\hline Zone3 & -0.8 & -0.42 & 0.32 & -0.48 & -0.4 & -0.92 \\
\hline Zone4 & -1.02 & -0.56 & -0.48 & 0.32 & -0.88 & -1.02 \\
\hline Zone5 & -0.92 & -0.34 & -0.4 & -0.88 & 0.32 & -0.6 \\
\hline Zone6 & -1.36 & -0.72 & -0.92 & -1.02 & -0.6 & 0.32 \\
\hline
\end{tabular}

Using the formulas below, the probability of various modes (Table 9-10) is measured using the Tables 7-8

$$
\text { Probability }_{\text {car }}=\frac{e^{U_{C a r}}}{e^{U_{C a r}}+e^{U_{A u t o}}}
$$

probability $_{\text {auto }}$

$$
\mathrm{e}^{\text {uauto }}
$$


Table 9: Probability matrix for car

\begin{tabular}{|l|l|l|l|l|l|l|}
\hline O-D & Zone1 & Zone2 & Zone3 & Zone4 & Zone5 & Zone6 \\
\hline Zone1 & 0.52 & 0.29 & 0.24 & 0.35 & 0.26 & 0.22 \\
\hline Zone2 & 0.29 & 0.52 & 0.26 & 0.22 & 0.30 & 0.29 \\
\hline Zone3 & 0.24 & 0.26 & 0.52 & 0.49 & 0.29 & 0.26 \\
\hline Zone4 & 0.35 & 0.22 & 0.49 & 0.52 & 0.17 & 0.33 \\
\hline Zone5 & 0.26 & 0.30 & 0.29 & 0.17 & 0.52 & 0.37 \\
\hline Zone6 & 0.22 & 0.29 & 0.26 & 0.33 & 0.37 & 0.52 \\
\hline
\end{tabular}

Table 10: Probability matrix for rickshaw

\begin{tabular}{|l|l|l|l|l|l|l|}
\hline O-D & zone1 & zone2 & zone3 & zone4 & zone5 & zone6 \\
\hline zone1 & 0.4756 & 1.1 & 0.7503 & 0.6035 & 0.7897 & 0.7732 \\
\hline zone2 & 0.5576 & 0.4628 & 0.7327 & 0.7614 & 0.696 & 0.7044 \\
\hline zone3 & 0.6488 & 0.6572 & 0.4756 & 0.6876 & 0.6745 & 0.738 \\
\hline zone4 & 0.649 & 0.6794 & 0.6766 & 0.4756 & 0.8219 & 0.6695 \\
\hline zone5 & 0.5182 & 0.6433 & 0.7075 & 0.8186 & 0.4756 & 0.6023 \\
\hline zone6 & 0.6183 & 0.7045 & 0.738 & 0.6695 & 0.6023 & 0.4628 \\
\hline
\end{tabular}

The modal share is now determined by multiplying the number of trips made from one zone to another (from the trip distribution) by the probability (Table 9-10). The following equation is used to measure this: Modal share for any mode $=$ Trip $_{i-j} *$ Probability $_{i * j}$

\section{Table 11}

\begin{tabular}{|l|l|l|l|l|l|l|}
\hline o-d & zone1 & zone2 & zone3 & zone4 & zone5 & zone6 \\
\hline zone1 & 70 & 51 & 14 & 23 & 10 & 11 \\
\hline zone2 & 30 & 71 & 18 & 12 & 22 & 17 \\
\hline zone3 & 17 & 20 & 51 & 25 & 24 & 14 \\
\hline zone4 & 21 & 16 & 26 & 48 & 10 & 20 \\
\hline zone5 & 17 & 26 & 21 & 10 & 70 & 42 \\
\hline zone6 & 15 & 17 & 11 & 19 & 44 & 0.53 \\
\hline
\end{tabular}

Table 12: Modal share matrix for rickshaw

\begin{tabular}{|l|l|l|l|l|l|l|}
\hline o-d & zone1 & zone2 & zone3 & zone4 & zone5 & zone6 \\
\hline zone1 & 63 & 70 & 36 & 36 & 31 & 31 \\
\hline zone2 & 45 & 62 & 43 & 37 & 51 & 42 \\
\hline zone3 & 32 & 40 & 62 & 54 & 50 & 36 \\
\hline zone4 & 38 & 34 & 54 & 63 & 32 & 40 \\
\hline zone5 & 25 & 47 & 52 & 32 & 63 & 66 \\
\hline zone6 & 24 & 42 & 30 & 40 & 20 & 86 \\
\hline
\end{tabular}

Finally, the modal distribution tables 11-12 for the two vehicles are arranged. This is the end outcome of the modal selection stage. We can see how many trips are made between zones using various modes of transportation. 


\section{TRIP ASSIGNMENT}

The traveller's route option to the total or part of a network is specified by the traffic assignment method. The inter-zonal modal trips are allocated to the different routes of each mode in the final step of the travel estimation process. At least four factors influence people's decision to take one path over another. They are as follows:

\section{Duration of travel}

2 Travel expenses

\section{Convenience and Service level (volume/capacity)}

The most commonly used considerations are travel time and prices.

The process starts with determining the shortest route. From any point of origin to any point of destination. Each O-D pair's trips are then allocated to the minimum path's links, and the trips are counted for each connection. To determine if the connection is congested, the allocated trip volume is compared to the link's capacity. If there is a When a connection becomes congested, its speed must be decreased, resulting in a longer travel time As travel times change, the shortest path can change as well. As a result, the entire process is repeated several times until travel demand and supply are in balance. Trips on overcrowded routes will be rerouted to traffic free routes before this equilibrium is reached. The most difficult calculation in the travel modelling series is traffic assignment.

The shortest distance in terms of GTC from one node to the other node for different modes is now calculated using Dijkstra's Method. For calculating the traffic flow for various modes from one node to another, an all-or-nothing assignment is used. After assuming a network, the Generalized Travel Cost (GTC) factor for each mode is calculated. The steps for calculating GTC are given below.

Where $\frac{a_{1}}{a_{2}}=\frac{0.060}{0.040}=1.5$

$$
G T C=T C+\left(\frac{a_{1}}{a_{2}}\right) * T T
$$

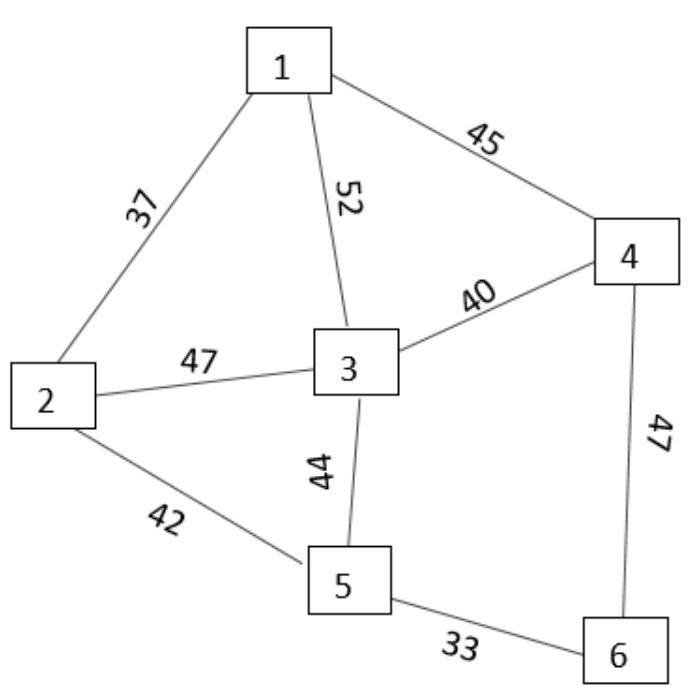

Generalized Travel Cost for Car

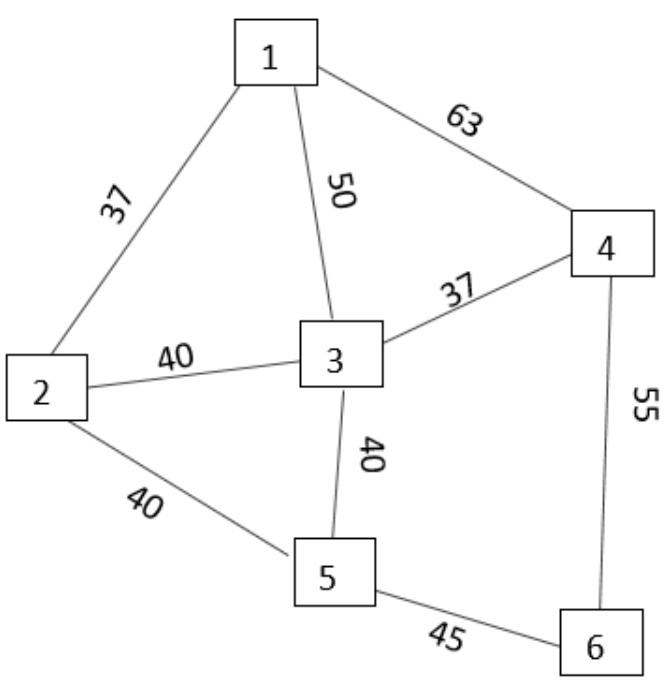

Generalized Travel Cost for Rickshaw

Figure 6: Generalized Travel Cost (GTC) for car and rickshaw 
Figure 7 displays the traffic flow from one node to another during peak hours for various modes of traffic:

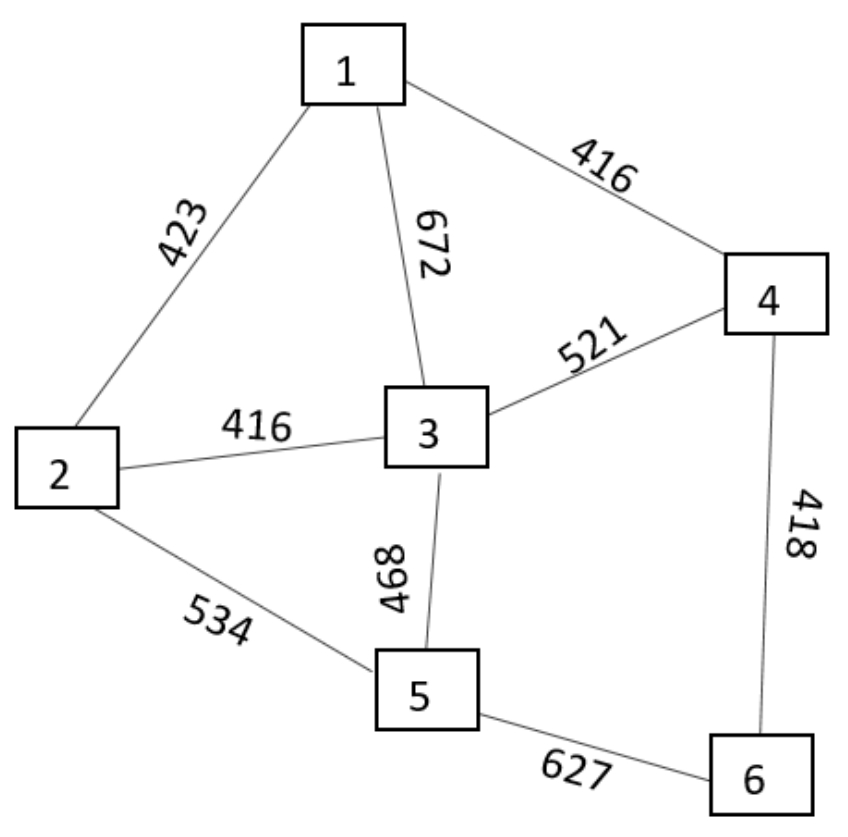

Traffic Flow for Car

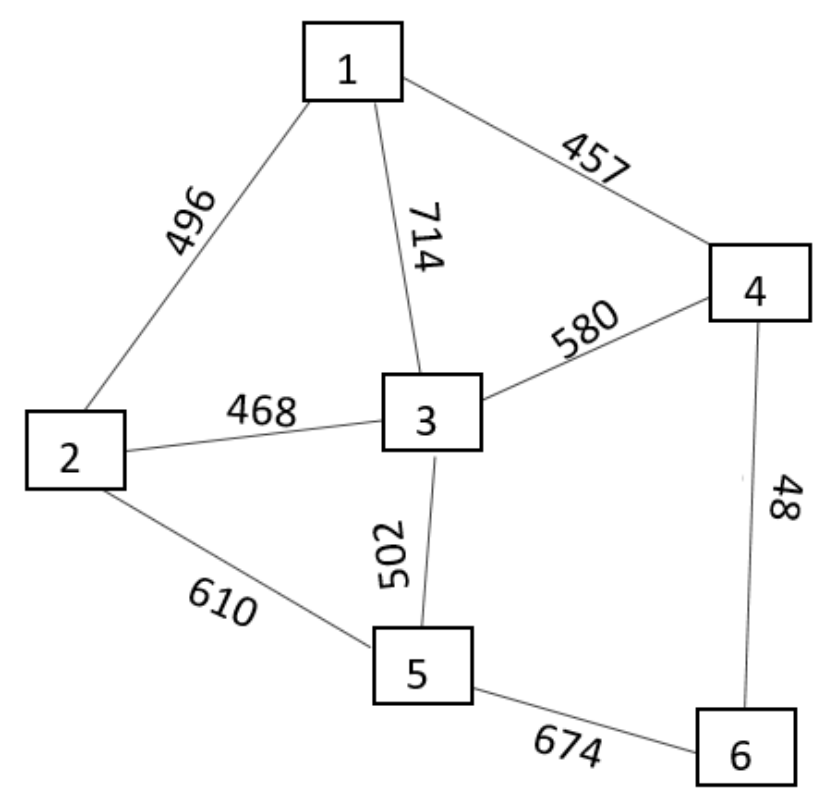

Traffic Flow of Auto-rickshaw

Figure 7: Total trips in each link for different modes at peak hour

The average number of people that occupy a vehicle is referred to as its occupancy. According to the Ulhasnagar corporation survey, the occupancy for a car is 1.85 , for a bus is 1.63 , and for a rickshaw is 1.85. The number of cars and rickshaws that flow in the peak time in different links is estimated using these occupancy values.

The total number of vehicles for a particular mode can be calculated from the formula:

Total No of vehicles $=$ Flow of that vehicle / Occupancy of that vehicle

Table 13: Total number of modes in each link at peak hours

\begin{tabular}{|l|l|l|l|l|l|l|}
\hline Link & Flow & occupancy & Number & Flow & Occupancy & Number \\
\hline & Car & car & Car & auto & auto & Auto \\
\hline $\mathbf{1 ~ 2}$ & 423 & 1.85 & 228 & 496 & 1.63 & 304 \\
\hline $\mathbf{1 ~ 5}$ & 672 & 1.85 & 363 & 714 & 1.63 & 438 \\
\hline $\mathbf{2 ~ 3}$ & 416 & 1.85 & 224 & 457 & 1.63 & 280 \\
\hline $\mathbf{2 ~ 4}$ & 534 & 1.85 & 288 & 610 & 1.63 & 374 \\
\hline $\mathbf{3 4}$ & 468 & 1.85 & 252 & 502 & 1.63 & 307 \\
\hline $\mathbf{3 6}$ & 627 & 1.85 & 338 & 674 & 1.63 & 413 \\
\hline $\mathbf{4 5}$ & 416 & 1.85 & 224 & 468 & 1.63 & 287 \\
\hline $\mathbf{4 6}$ & 521 & 1.85 & 281 & 580 & 1.63 & 355 \\
\hline $\mathbf{5 6}$ & 418 & 1.85 & 225 & 482 & 1.63 & 295 \\
\hline
\end{tabular}


The traffic assignment details reflect the amount of travel that can be expected on each path in the network with a given transportation system at some point in the future. Congestion levels, travel times, travel speeds, and vehicle miles travelled are all direct outputs of the modeling process. For plan evaluation, connection traffic volumes are often used to assess other travel results.

Thus, the existing transport modelling process is carried out step by step, as detailed in this paper, while collecting data for the 6 zones of the Ulhasnagar City Corporation for research purposes.

\section{IV.CONCLUSION}

By integrating theory and practice, transportation modeling was used to investigate and solve "absolute" problems. Four traditional models will be developed for future planning. The total number of trips created to and attracted from different zones in the study area is estimated using trip generation. The trip matrix can be used to define the trip distribution pattern in the study field. The trip matrix is calculated using the gravity model and the growth factor equation. The number of trips taken by people who use a particular mode of transportation is determined by mode selection. The model Logit is used in this method. By comparing the outcomes of their trip, travellers would select the path with the shortest route time and distance. One of the most critical ways to enhance model accuracy and value is to build a good set of recent data to calibrate the models and provide for accuracy assessments. Travel demand management, employer-based trip reduction systems, pedestrian and cycling programmers, changing population age structure, and land use policies are not covered by this approach. In order to make the traditional transportation modelling system more realistic and practical, several important points should be considered and implemented.

\section{REFERENCES}

[1]. L.R., Traffic Engineering, and Transport Planning, Delhi: Khanna Publishers, 2004.

[2]. Bayes Ahmed, the Traditional Four Steps Transportation Modeling Using Simplified Transport Network: A Case Study of Dhaka City (Bangladesh), volume 1, article 3, February 2012.

[3]. P.N. Dadhich, Arun Singh Shekhawat, Ankush Kumar, Ankit Yogi, Ankit Kumar, and Abhinav Sharma, Travel Demand Modelling and Forecasting (A Case Study of Sitapura Industrial Area), (IJERT), 2016.

[4]. Ulhasnagar city population census 2011-2021, Maharashtra.

[5]. Revised development plan for Ulhasnagar Municipal Corporation (2010-2035), Dist. Thane, sanctioned under section of 31(1) of MR and TP Act, 1966

[6]. Arun Chatterjee and Mohan M. Venigalla, Travel demand forecasting for urban transportation planning, Venigalla, et al. (1995a, 1995b, 1999), and Chatterjee, et al. (1996), Explain the procedure, paper published in 2018.

[7]. Kevin B. Modi, Dr. L. B. Zala, Transportation Planning Models: A Review, B. V. M. Engg. College Gujarat, India, National Conference on Recent Trends in Engineering \& Technology, May 2011.

[8]. WERNER HEYNS \& SIMON VAN JAARSVELD, TRANSPORTATION MODELLING IN PRACTICE: CONNECTING BASIC THEORY TO PRACTICE, 
Transportation, Land Use and Integration: Perspectives for Developing Countries, 2017.

[9]. WisineeWisetjindawat\& Kazushi Sano, A behavioralmodeling in micro-simulation for urban freight transportation, Research Gate, January 2003.

[10]. Tom V. Mathew, Travel Demand Modelling, Indian Institute of Technology Bombay, Transportation Systems Engineering, December 4, 2012.

[11]. Theodore Tsekeris\&CharalambosTsekeris, Demand Forecasting in Transport: Overview and Modeling Advances, Economic ResearchEkonomskaIstraživanja, November 9, 2015.

[12]. McNally, Michael G., The Four-Step Model, Institute of Transportation Studies University of California, November 17, 2008.

[13]. Sandeep SambhajiUdmale\& Vijay SambheVeermataJijabai Technological Institute, Extended Four-Step Travel Demand Forecasting Model for Urban Planning, Research gate publication, January 2018.

[14]. Milos MladenovicThe Shortcomings of the Conventional Four-Step Travel Demand Forecasting Process, Research gate publication, June 2014.

[15]. Moshe Ben-Akiva, Travel Demand Modeling, Transportation Systems Analysis: Demand \& Economics, 2008.

[16]. Sujesh D.Ghodmare, Dr.B.V.Khode, and Dr. Preeti Bajaj, Application of the Multi-Attribute Utility Technique with ITS For Sustainability Evaluation of the Emerging Metropolitan City of Nagpur. International Journal of Civil Engineering and Technology, 10(01), 2019, pp. 942-950

\section{Cite this article as :}

Geetanjali Yadav, Sujesh D Ghodmare, "Transportation Planning Using Conventional Four Stage Modeling : An Attempt for Identification of Problems in a Transportation System", International Journal of Scientific Research in Science and Technology (IJSRST), Online ISSN : 2395-602X, Print ISSN : 2395-6011, Volume 8 Issue 4, pp. 556-567, July-August 2021. Available at doi : https://doi.org/10.32628/IJSRST218482 Journal URL : https://ijsrst.com/IJSRST218482 